\title{
Chlamydia Infection in Patients With and Without Cervical Intra-Epithelial Lesions Tested by Real-Time PCR vs. Direct Immunofluorescence
}

\begin{abstract}
Micheline de Lucena Oliveira, Melania Maria Ramos de Amorim, Paulo Roberto Eleutério de Souza, Lúcia Cristina Bezerra de Albuquerque, Lucas André Cavalcanti Brandão and Rafael Lima Guimarães

Prof. Fernando Figueira Institute (IMIP); Public Health Laboratory of Recife; Laboratory of Immunopathology; Keizo-Azami (LIKA); Recife, PE, Brazil
\end{abstract}

\begin{abstract}
This study compares the detection rates of Chlamydia trachomatis by two techniques, direct immunofluorescence (IMF) and real time polymerase chain reaction (PCR), in patients with and without intra-epithelial cervical lesions (SIL) in Recife. We conducted a transversal study involving 35 women with SIL and 35 without SIL attended at Ambulatório Especializado da Mulher, Recife, Brazil. They were tested for Chlamydia trachomatis using two techniques, direct IMF or real time PCR. The rates of Chlamydia trachomatis detection were compared and the association with intra-epithelial cervical lesions was determined using the chi-square test at a $5 \%$ level of significance. Concordance between the tests was evaluated using kappa. The global prevalence of Chlamydia infection was $47.1 \%$ by direct IMF and $58.6 \%$ by real time PCR. A significant association was observed between Chlamydia diagnosis and presence of intra-epithelial cervical lesions, with about $80 \%$ positive results by direct IMF and $77.1 \%$ by real time PCR. However, the detected rate of infection with Chlamydia trachomatis was significantly greater in patients without intra-epithelial cervical lesions tested by real time PCR (40\%) when compared to direct IMF (14.3\%). The concordance between the tests was weak, with a kappa coefficient of 0.4. Both real time PCR and direct IMF detected elevated rates of Chlamydia infection in patients with intra-epithelial cervical lesions (80\%) but the tests were discordant when patients without cervical lesions were tested, possibly because sensitivity of real time PCR is greater.
\end{abstract}

Key-Words: Chlamydia trachomatis, Chlamydia infections, fluorescent antibody technique direct, polymerase chain reaction.

Infection by Chlamydia trachomatis has been recognized as an important problem for public health [1]. The World Health Organization estimates that approximately 50 million cases of infection by Chlamydia trachomatis occur per year worldwide [2]. Chlamydia trachomatis infection of the genital tract can cause inflammatory pelvic disease, venereal lymphogranuloma, urethritis, cervicitis, salpingitis, bartholinitis, endometritis, tubarian infertility and ectopic pregnancy [2-4]. The health costs due to complications caused by this type of infection are elevated. In the United States, an estimated 2.7 billion dollars were spent in 1990 for direct medical costs due to pelvic inflammation disease, with two frequent complications, ectopic pregnancy and infertility [5].

Approximately $70 \%-75 \%$ of the genital infections in women are asymptomatic [2]. Consequently, these infectious agents can be considered microorganisms that are well adapted to the human body, because they can grow without causing strong responses from the organism, which is the reason it is difficult to diagnose such infections [6]. This peculiarity retards treatment, allowing cases of genital infection to propagate to the upper genital tract, causing endometritis and salpingitis [2-4].

In 2005, 976,445 cases of genital infection caused by Chlamydia trachomatis were reported to the Centers for

Received on 28 March 2008; revised 29 July 2008.

Address for correspondence: Dr. Melania Maria Ramos de Amorim. Rua Neusa Borborema de Souza, 300, Bairro Santo Antônio. Campina Grande - PB. Zip code: 58103-313. E-mail: melamorim@uol.com.br.

The Brazilian Journal of Infectious Diseases

2008;12(4):324-328. (C) 2008 by The Brazilian Journal of Infectious Diseases and Contexto Publishing. All rights reserved.
Disease Control and Prevention (CDC) in the USA, corresponding to a rate of 332.5 cases per 100,000 inhabitants. The prevalence in women from individual states varies from $3.1 \%$ to $14.5 \%$ (median $=9.2 \%$ ), being still higher in adolescents, with a median rate of infection with Chlamydia of $14.2 \%$ (varying from 3.7 to 33.7\%) [7]. Official data on infection prevalence are not available in Brazil [8].

Various methodologies can be used to detect Chlamydia trachomatis. Choice of a method should take into consideration the prevalence of infection in the population, to define the methodology that is most sensitive, specific and reproducible [9]. Also, it is important to consider the costs/ benefits of the test, the difficulties associated with it use, as well as the equipment, laboratory infrastructure and time needed to produce results [9].

The most widely used methods are detection of Chlamydia trachomatis antigens in the clinical sample. This is a viable diagnostic method that gives acceptable results. Direct immunofluorescence consists of the identification of elementary corpuscles in endocervical material, through fluorescent monoclonal antibodies, identified with an optical microscope $[9,10]$. This technique uses one or more monoclonal antibodies against the main protein found in the external membrane of Chlamydia trachomatis, conjugated with fluorescent molecules. The sensitivity with this method reaches $95 \%$ and the specificity up to $100 \%[9,10]$.

Currently, the "gold standard" for diagnosing Chlamydia trachomatis is cell culture; however, the rapid evolution of DNA amplification techniques (PCR and LCR, for example), is leading to a reevaluation of this standard by the scientific community [9]. Cell culture is a very precise diagnostic method; 
however, its extremely high cost and the need for sophisticated techniques of live cell culture make this technique unpractical for clinical practice $[9,10]$.

PCR rapidly detects small quantities of nucleic acids in clinical samples. The sensitivity of these DNA amplification tests is approximately $20 \%$ greater than cell culture, direct immunofluorescence and enzyme immunoassays. Though they are more expensive, they increase the diagnostic capacity for this disease, with a sensitivity of 98.0\%-99.9\% [10-12].

Recently, a technological innovation that came from PCR, named real-time PCR, has become more common for clinical diagnostics and in research labs, because of its ability to generate quantitative results. The main advantages are the possibility of quantification, along with greater sensitivity, precision and accuracy, as well as faster analysis, making this technique superior to the other methods [11,12]. This technique allows one to accompany the reaction and gives faster and more precise results than standard PCR, which only gives qualitative results [11-13]. It can be run totally in vitro without using cells [12,13], and it quantifies DNA and RNA precisely and with greater reproducibility, because it determines values during the exponential phase of the reaction [11-13]. Its sensitivity makes it possible to use a very small sample, with extremely small residues of blood or tissue, even parts of a single cell $[11,12]$. The time needed to produce a result is approximately two hours; the other techniques need more time for processing the material.

We compared the rate of detection of infection by Chlamydia trachomatis with two techniques (direct IMF and real time PCR) in samples from patients who had pre-cervical cancer lesions (or not) attended at a public medical service in Recife city.

\section{Material and Methods}

We made a transverse study to compare the rates of detection of infection by Chlamydia trachomatis using direct immunofluorescence and real-time PCR of patients with or without precancer lesions in the uterine cervix, who were attended at the Women's Ambulatory Service of the municipality of Recife, from November 2006 to April 2007.

The study population consisted of 70 women who had oncological cytology exams made at municipal and/or state health services, who had (or not) lesions with low or high frequency of "atypical glandular cells of undetermined significance” (ASCUS/AGUS) for uterine cervical cancer and who had not been treated for uterine cervical cancer during the previous six months; HIV-positive women were excluded from the study (only one case detected and substituted with another patient).

The size of the sample was calculated with the software EPI-INFO 3.3.2, using the program STATCALC, based on prevalence data from the literature. Though various authors had reported higher frequencies, we based our sampling numbers on the study made by Golijow et al. (2005) [14] in Argentina, since that population apparently has similar characteristics, to evaluate the prevalence of Chlamydia trachomatis in patients with normal and abnormal oncotic cytologies. We analyzed 279 women and observed that the prevalence of Chlamydia trachomatis infection was $11 \%$ in patients with normal oncotic cytologies, while in patients with lesions with low and high grade ASCUS, there was an increase to $47 \%$, when we used PCR techniques. Considering an infinite population, with a precision of $5 \%$, a level of confidence of $95 \%$, and a power of $80 \%$, the indicated sample size would be 58 women. To compensate possible losses, we increased the number approximately $20 \%$ to 70 women, including 35 with normal oncotic cytologies and 35 with abnormal cytologies (precancer lesions with low and or high grade ASCUS). This study was previously approved by the Ethics in Research Committee of IMIP and all the patients who were included signed an informed consent form.

Medical data forms were filled out, and exams were made of the patients, including colposcopy, biopsies (when necessary) and vaginal content and endocervical cultures to check for Chlamydia trachomatis by direct immunofluorescence and real-time PCR; HIV tests were solicited for patients who had not been tested in the previous six months. After this initial visit, return visits were programmed for treatment and accompaniment of each case.

The variables included in the analysis were age, race, precedence, schooling, parity, number of sexual partners, secretions, previous Papanicolaou exams, episodes of sexually transmitted diseases (based on patient-supplied information), electrocauterization, contraceptive methods, alcohol consumption, smoking habits, and the results of the cytology and cervical infection by Chlamydia trachomatis by the two methods (direct immunofluorescence and real-time PCR).

We considered as normal cytology the cytologies with superficial, intermediate and/or endocervical squamous cells without abnormalities; with squamous metaplasia and/or with inflammatory alterations; and as abnormal cytologies those that were diagnosed with low or high grade lesions, squamous carcinoma, atypical escamosas cells of undetermined significance and atypical glandular abnormalities of undetermined significance.

Infection by Chlamydia trachomatis based on the direct immunofluorescence method was considered when monoclonal antibodies against the membrane protein of of Chlamydia trachomatis were evidenced by fluorescence. In this case, the marked antibody (conjugate) binds specifically with the Chlamydia trachomatis proteins in the endocervical or urethral smear fixed with acetone. The unlinked antibodies are removed by washing. When observed with a fluorescent microscope, Chlamydia trachomatis exhibits a brilliant applegreen fluorescence and can be detected at all stages of development, including elementary bodies and reticular bodies. Samples were considered positive when there were at least five clamidia particles; when there were fewer, positivity was considered when there was no doubt that the particles were Chlamydia (and not artifacts). A sample was considered

www.bjid.com.br 
negative when clamidia bodies were not present, but epithelial cells with more or less elongated geometric forms were present, attesting to the quality of the sample.

The clinical samples were considered positive by real-time PCR when specific primers for rDNA sequences amplified $16 \mathrm{~S}$ ribosomal RNA of Chlamydia trachomatis.

Clinical samples were treated with detergents or the microorganisms were lysed with heat treatment to extract DNA for analysis. The extracted DNA was placed in a tube containing all of the reagents needed for the PCR reaction [11-13].

Collection of samples consisted of inserting a speculum (without lubricant) into the vagina (of women who were not menstruating, using vaginal duches or vaginal creams the day before and after three days of sexual abstinence), removing the excess cervical mucus, and after inserting the cotton swab into the endocervical canal until the tip was no longer visible, rotating it for some seconds, removing it, avoiding contact with the vaginal canal and smearing the swab onto a cytological slide that was duly labeled. After drying completely at room temperature, the slide was fixed with acetone by immersion, during 10 minutes. After the fixative had evaporated completely, the slides were placed into appropriate containers and sent to the Public Health Laboratory of the Municipality of Recife, being processed within 24h of the collection and normally within a few hours after collection. The direct immunofluorescence analysis was done with Chlamydia Direct IF kits, from BioMérieux; five hemorrhagic samples and one purulent sample were rejected, and new samples were collected from these patients.

After this procedure, ectocervical samples were collected with an Aires spatula and endocervical samples with an endocervical brush, rotating it for a few seconds and avoiding touching the vaginal wall. This material was agitated in $15 \mathrm{~mL}$ of $0.9 \%$ SF, and refrigerated for later processing by the Keizo Azami immunopathology laboratory. The professionals who were responsible for these diagnostic procedures were not aware of whether the patients had intra-epithelial cervical lesions.

Real-time PCR was done with a Rotor-Gene 3000 (Corbett Robotics, Australia). The reactions were run in a final volume of $25 \mu \mathrm{L}$ containing SyberGreen Real Time Mastermix (Applied Biosystems), $1 \mathrm{mM}$ of the forward primer (5'TCGAGAATCTTTCGCAATGGAC), $1 \mathrm{mM}$ of the reverse primer (5'CGCCCTTTACGCCCAATAAA) and $2 \mu \mathrm{L}$ of extracted DNA [15]. The PCR cycle program consisted of an initial denaturating cycle of $95^{\circ} \mathrm{C}$ for $10 \mathrm{~min}$ and 40 repetitions of cycles of $95^{\circ} \mathrm{C}$ for $10 \mathrm{~s}$ and $60^{\circ} \mathrm{C}$ for $65 \mathrm{~s}$ [15].

Patients who were diagnosed to have Chlamydia based on direct immunofluorescence (IMF) or by real-time PCR were treated with one gram of azitromicina via oral, in a single dose. Patients with altered cytology were cared for according to the procedures established by the Health Ministry [16].

The data were stored, revised and analyzed with the software Epi-Info version 3.4.1, with double entries. To determine concordance between IMF-Chlamydia and realtime PCR, we used a kappa test, in which 1.0 expresses maximum concordance and 0.0 total lack of concordance. In order to evaluate whether these is any difference between the percentage positivity of IMF-Chlamydia and of real-time PCR in all of the women, according to whether they had intraepithelial lesions or not, we used the chi-square test for association (Pearson). The alpha value for significance was set at $5 \%$.

\section{Results}

Among the 70 patients (half of whom had intra-epithelial cervical lesions), the overall rate of infection with Chlamydia was $47.1 \%$ by direct IMF and $58.6 \%$ by real-time PCR (Table 1). The frequency of infection by Chlamydia determined by both methods was significantly higher in patients with intraepithelial cervical lesions, $77.1 \%$ with direct IMF and $80 \%$ with real-time PCR (no significant difference between them). However, the frequency of infection by Chlamydia trachomatis was significantly higher in patients who had no intra-epithelial lesions in the cervix when analyzed by realtime PCR (40.0\%) than with direct IMF (14.3\%) (Table 2).

There was a weak concordance between the two tests, giving a kappa coefficient of 0.4 , with differences between the negative and positive diagnoses for Chlamydia from realtime PCR compared to direct IMF (Table 3).

\section{Discussion}

We observed prevalences of infection by Chlamydia trachomatis of $47.1 \%$ and $58.6 \%$ with direct IMF and real-time PCR, respectively. This difference was not significant. Among patients with intra-epithelial cervical lesions, direct IMF and real-time PCR gave similar percentages of infection by Chlamydia trachomatis (77.1\% for PCR and $80.0 \%$ for realtime PCR); however the rate of infection with Chlamydia trachomatis detected with real-time PCR in patients with negative cytology was nearly three times higher (40.0\%) than the rate detected with direct IMF (14.3\%). This difference was significant. There was weak concordance between these techniques, evidenced by the 0.4 kappa value.

Michael et al. [17] analyzed the sensitivity and specificity of PCR for detecting Chlamydia trachomatis in cervical secretions and the urine of asymptomatic women. They obtained a sensitivity of $92.8 \%$ and a specificity of $99.7 \%$ for cervical samples; the sensitivity was reduced to $85.5 \%$ for

Table 1. Rates of infection with Chlamydia with the different detection techniques.

\begin{tabular}{lccllc}
\hline Infection by Chlamydia & \multicolumn{2}{c}{ IMF } & & \multicolumn{2}{c}{ PCR } \\
\cline { 2 - 3 } \cline { 6 - 6 } & $\mathbf{N}$ & $\mathbf{\%}$ & & $\mathbf{N}$ & $\mathbf{\%}$ \\
\hline Present & 33 & 47.1 & & 41 & 58.6 \\
Absent & 37 & 52.9 & & 29 & 41.4 \\
\hline
\end{tabular}

$\chi^{2}=2.33 ; p=0.13$. 
Table 2. Comparison of real-time PCR results and direct IMF based on cytology results.

\begin{tabular}{|c|c|c|c|c|c|c|c|c|c|c|}
\hline \multirow[t]{3}{*}{ Oncotic cytology } & \multicolumn{4}{|c|}{ Real-time PCR } & \multicolumn{4}{|c|}{ IMF-Chlamydia } & \multirow[t]{3}{*}{$\chi^{2}$} & \multirow[t]{3}{*}{$\mathbf{p}$} \\
\hline & \multicolumn{2}{|c|}{ Positive } & \multicolumn{2}{|c|}{ Negative } & \multicolumn{2}{|c|}{ Positive } & \multicolumn{2}{|c|}{ Negative } & & \\
\hline & $\mathbf{N}$ & $\%$ & $\mathbf{N}$ & $\%$ & $\mathbf{N}$ & $\%$ & $\mathbf{N}$ & $\%$ & & \\
\hline Altered & 27 & 77.1 & 8 & 22.9 & 28 & 80.0 & 7 & 20.0 & 0.08 & 0.77 \\
\hline Normal & 14 & 40.0 & 21 & 60.0 & 5 & 14.3 & 30 & 85.7 & 5.85 & 0.016 \\
\hline$\chi^{2}$ & & 9.95 & & & & 30.33 & & & & \\
\hline $\mathrm{p}$ & & 0.002 & & & & 000000 & & & & \\
\hline
\end{tabular}

Tabela 3. Concordance between IMF and PCR.

\begin{tabular}{|c|c|c|c|c|}
\hline \multirow[t]{3}{*}{ PCR } & \multicolumn{4}{|c|}{ IMF } \\
\hline & \multicolumn{2}{|c|}{ Positive } & \multicolumn{2}{|c|}{ Negative } \\
\hline & $\mathbf{N}$ & $\%$ & $\mathbf{N}$ & $\%$ \\
\hline Positive & 27 & 65.9 & 14 & 34.1 \\
\hline Negative & 06 & 20.7 & 23 & 79.3 \\
\hline
\end{tabular}

Карpa=0.434; EP of Kappa=0.116; Z=3.73; p=0.000096.

urine samples and the specificity was $99.5 \%$. Shrier et al. [18] evaluated 126 patients using various methods, including culture techniques, PCR and LCR, examining urethral secretions (culture and PCR), as well as vaginal (PCR), endocervical (culture, PCR and LCR) and urine samples (PCR and LCR). They found a prevalence of 22\% Chlamydia trachomatis. The sensitivities were similar for PCR and LCR ( $52 \%$ versus $63 \%$ ); however, sensitivity was different for PCR of urine (44\%) and was reduced with diagnosis by culture (22\%-37\%); the specificities varied from $99 \%$ to $100 \%$, except for LCR of the urine (91\%).

In a study made in Taiwan, using PCR, the general prevalence was $18.4 \%$ (95\% CI $=17.3-19.5)$, being $16.7 \%$ in men and $22.8 \%$ in women (95\% CI=17.5-28.1\%). The prevalence in the different age groups was $25.7 \%$ for less than 20 years, $23.5 \%$ from 20 to 24 years; $22.3 \%$ from 25 to 30 years and $11.5 \%$ more than 30 years old [19].

One hundred and twenty-three samples of endocervical secretions from married women 20-55 years old were analyzed in Iran. The frequency of Chlamydia trachomatis was 17\% (12-25\%) using PCR - EIA. Higher frequencies were found in the 31-40 year old subgroup (49\%) and in the $20-30$ year-old subgroup (33\%) [20].

Frias et al. [10] used an ELISA test and found Chlamydia trachomatis in 5\% of sexually active women $13-49$ years old in Teresópolis, Rio de Janeiro, who were not using oral or vaginal antibiotics during the 15 days before the exam. Santos et al. [21] reported a prevalence of $20.7 \%$ for Chlamydia trachomatis in Manaus using PCR.

In São Paulo, in a study made at the Hospital das Clínicas, 189 cervical samples were analyzed with direct IMF with monoclonal antibodies, with McCoy cell culture and by testing for IgG and IgA antibodies. Chlamydia trachomatis was identified in $8.4 \%$ of the women with symptoms and $13 \%$ of those without symptoms [6].
We found a high frequency of patients with Chlamydia trachomatis detected both by PCR and direct IMF in patients with intra-epithelial cervical lesions (about $80 \%$ ), suggesting that the two methods are equally sensitive for detecting Chlamydia trachomatis in these patients. It could be argued that the high frequency of infection does not justify routine testing for Chlamydia trachomatis in patients with intraepithelial cervical lesions, since systematic treatment of this type of infection would be a more effective cost/benefit approach. However, some professionals are reticent to treat infection without being sure of the diagnosis; this question merits further studies.

We found large differences in the frequency of infection with Chlamydia trachomatis detected by real-time PCR (40\%) versus direct IMF (14.3\%) in the subgroup of patients with negative cytological tests. This could be due to the greater sensitivity of PCR for the various serotypes of Chlamydia trachomatis. Various other studies have also demonstrated that real-time PCR is more sensitive than culture techniques for analyzing samples from cervicitis e urethritis [10], rapidly detecting very small quantities of nucleic acids in clinical samples, independent of how they have been collected [11,12]. This test can detect even a single plasmid particle of Chlamydia trachomatis, due to the production of thousands of copies of a DNA segment from primers and a DNA-target sequence $[11,12]$.

There are 15 different serotypes of Chlamydia trachomatis, which can cause various different diseases. Serotypes L1, L2 and L3 cause lymphogranuloma venereum; serotypes A, B, Ba and C cause trachoma; and D,E,F,G,H,I,J and $\mathrm{K}$ can cause inclusion conjunctivitis, urethritis, cervicitis, salpingitis and pneumonia in new-borns [9,13]. The primer that we used is specific for Chlamydia trachomatis; however, it does not allow us to type the serotypes. We quantified the frequency of Chlamydia trachomatis; however, we still need to be able to identify specific serotypes in order to determine which serotypes are more frequent in patients with and without intra-epithelial lesions. We also need to determine whether certain serotypes are associated with lesions and symptoms in the reproductive tract (especially tubular obstruction).

Further studies are needed to evaluate the impact of this type of diagnosis of infection by Chlamydia trachomatis in patients without oncotic cytology alterations, in order to determine whether it is worthwhile to include real-time PCR in 
tests of the general population or in patients at risk for Chlamydia trachomatis infection, or if it we better to use direct IMF. Analyzing the frequency of symptoms and the effects of Chlamydia on the subsequent reproductive capacity of affected individuals is important for elaborating detection strategies. Though treatment of infection by Chlamydia trachomatis is relatively simple and low cost, the involvement of $40 \%$ would result in the treatment of many women, without proof of beneficial effects in terms of prevention of tubarian obstruction and infertility.

\section{Acknowledgements}

The authors thank the Instituto Materno-Infantil Prof. Fernando Figueira (IMIP), the Laboratório de Saúde Pública Municipal da Prefeitura do Recife, the Laboratório de Imunopatologia Keizo-Azami (LIKA) and the Ambulatório Especializado da Mulher da Prefeitura do Recife-AMEM for their collaboration in this research.

\section{References}

1. World Health Organization 2005. Sexually transmitted and other reproductive tract infections. Geneva, World Health Organization, 2005. Disponível em: http://www.who.int/reproductive-health/ publications/rtis_gep/rtis_gep.pdf [2007 Nov 20]

2. World Health Organization. Department of HIV/AIDS. Global prevalence and incidence of selected curable sexually transmitted infections. Geneva, World Health Organization, 2001. Disponível em: http://www.who.int/docstore/hiv/GRSTI/003.htm [2007 Nov 20]

3. Machado A.C.S., Guimarães E.M.B., Sakurai E., et al. High titers of Chlamydia trachomatis antibodies in Brazilian women with tubal occlusion or previous ectopic pregnancy. Infect Dis Obstet Gynecol 2007:24816.

4. Wiesenfeld H.C., Hillier S.L., Krohn M.A., et al. Lower genital tract infection and endometritis: insight into subclinical pelvic inflammatory disease. Obstetrics \& Gynecology 2002;100:456-63.

5. Rein D.M., Kassler W.J., Irwin K.L., Rabiee L. Direct medical cost of pelvic inflammatory disease and its sequelae: decreasing, but still substantial. Obstetrics \& Gynecology 2000;95:397-402.

6. Melles H.H.B., Colombo S., Linhares I.M., Siqueira L.F.G. Avaliação de parâmetros para o diagnóstico laboratorial de infecção genital feminina pela Chlamydia trachomatis. Rev Soc Bras Med Trop 2000;33:355-61.
7. Center for Disease Control and Prevention. Sexually transmitted disease Surveillance 2005 supplement. In: Chlamydia prevalence monitoring project annual report 2005. Atlanta, 2005. Disponível em: http://www.cdc.gov/std/Chlamydia2005/ CTSurvSuppComplete.pdf [2007 Out 8]

8. Ministério da Saúde, Brasil, Programa Nacional de DST/AIDS. Diagnóstico laboratorial de clamídia, Brasília, 1997. Disponível em: http://bvsms.saude.gov.br/bvs/publicacoes/ cd05_09.pdf.

9. Frias M.C.A.A., Pereira C.F.A., Pinheiro V.M.S., et al. Freqüência de Chlamydia trachomatis, Ureaplasma urealyticum e Mycoplasma hominis na endocérvice de mulheres no menacme. J Bras Doenças Sex Transm 2001;13:5-22.

10. Novais C.M., Alves M.P. PCR em tempo real. Revista Biotecnologia Ciência \& Desenvolvimento 2004;33:10-3.

11. Houghton S.G., Cockerill III F.R. Real-time: Overiew and applications. Surgery 2006;139:1-5.

12. Xia Q.-F., Xu S.-X., Wang D.-S., et al. Development of a novel quantitative real-time assay using duplex scorpion primer for detection of Chlamydia trachomatis. Experimental and Molecular Pathology 2007;1-6.

13. Golijow C.D., Abba M.C., Mouron A.S., et al. Chlamydia trachomatis and Human papillomavirus infections in cervical disease in Argentine women. Gynecol Oncol 2005;96:181-6.

14. Goldschmidt P., Rostane H., Sow M., et al. Detection by broadrange real-time PCR assay of Chlamydia species infecting humam and animals. 2006;90:1425-9.

15. Ministério da Saúde, Brasil. Caderno de Atenção Básica n 13. Controle dos cânceres do colo do útero e da mama. Brasília DF, 2006. Disponível em: http://bvsms.saude.gov.br/bvs/ publicacoes/abcad13.pdf [2007 Nov 20].

16. Spigarelli M.G., Biro F.M. Sexually transmitted disease testing: Evaluation of diagnostic tests and methods. Adolescent Medicine Clinics 2004;15:287-99.

17. Shrier L.A., Dean D., Klein E., et al. Limitations of screening tests for the detection of Chlamydia trachomatis in asymptomatic adolescent and young adult women. American Journal of Obstetrics and Gynecology 2004;190:654-62.

18. Chen K.-T., Chen S.-C., Chiang C.-C., et al. Chlamydial infection among patients attending STD and genitourinary clinics in Taiwan. BMC Public Health 2007;7:120.

19. Hashemi F.B., Pourakbari B., Yazdi J.Z. Frequency of Chlamydia trachomatis in women with cervicitis in Tehran, Iran. Infectious Diseases in Obstetrics and Gynecology 2007;2007.

20. Santos C., Teixeira F., Vicente A., Astolfi-Filho S. Detection of Chlamydia trachomatis in endocervical smears of sexually active women in Manaus-AM, by PCR. Brazilian Journal of Infectious Diseases 2003;7:91-5. 